\title{
Comparison of EGFR mutation rates in lung adenocarcinoma tissue and pleural effusion samples
}

\author{
Y. Guan, Z.J. Wang, L.Q. Wang, D.F. Hua and J. Liu \\ Department of Respiratory Medicine, Weifang People's Hospital, Weifang, \\ Shandong Province, China \\ Corresponding author: J. Liu \\ E-mail: papersunmmer@163.com
}

Genet. Mol. Res. 15 (2): gmr.15027001

Received June 16, 2015

Accepted December 4, 2015

Published April 4, 2016

DOI http://dx.doi.org/10.4238/gmr.15027001

\begin{abstract}
The goal of the current study was to investigate the differences in epidermal growth factor receptor (EGFR) mutation rates in tumor tissue and pleural effusion specimens from patients with lung adenocarcinoma. PCR amplification and gene sequencing were used to detect EGFR mutations in exons 18, 19, 20, and 21 in tumor tissue and pleural effusion samples from 50 patients with advanced lung adenocarcinoma. The EGFR mutation rate was $34.0 \%$ in tissue samples from patients with advanced lung adenocarcinoma. There were 11 cases with exon 19 mutations and 6 cases with exon 21 mutations. The EGFR mutation rate was $30.0 \%$ in pleural effusion specimens, including 10 cases with exon 19 mutation and 5 cases with exon 21 mutations. Although the tissue samples had a slightly higher mutation rate compared to the pleural effusion samples, the difference was not statistically significant. These results indicate that the EGFR mutation rate detected in pleural effusion specimens from patients with advanced lung adenocarcinoma is similar to that detected in tumor tissue samples. Therefore, pleural effusion specimens can potentially be used for EGFR mutation detection in advanced lung adenocarcinoma.
\end{abstract}

Key words: Lung adenocarcinoma; Pleural effusion; Gene sequencing; EGFR mutation 


\section{INTRODUCTION}

Cancer poses a serious threat to human health and commonly occurs in the respiratory tract, digestive tract, and reproductive system. Lung cancer has the highest incidence and mortality rates among malignant tumors worldwide and accounts for the highest incidence of cancer in China (Zhu et al., 2008; Mitsudomi et al., 2010; Fukuoka et al., 2011). Lung cancer is classified into two main types: non-small cell lung cancer (commonly adenocarcinoma and squamous cell carcinoma) and small cell lung cancer. Non-small cell lung cancer accounts for roughly $82 \%$ of all lung cancers, and lung adenocarcinoma accounts for about $80 \%$ of non-small cell lung cancers. Most early stage lung cancers have non-specific symptoms including cough, sputum, and blood in the phlegm. However, such symptoms often cause lung cancer to be confused with diseases such as tuberculosis and pneumonia. Hence, most lung cancers are diagnosed late, when they are no longer operable. Non-surgical treatment options include local radiotherapy and systemic chemotherapy, but these are often harmful to the body, especially for elderly patients over 70 years of age. Thus, it is important to find new treatment methods for elderly lung cancer patients or those who cannot tolerate radiation and chemotherapy. Targeted drug therapy for lung cancer has become a focus of current research (He et al., 2009; Zhang et al., 2010; Jiang et al., 2011). Currently, epidermal growth factor receptor (EGFR) gene mutations are the most widely investigated targets for therapy in lung adenocarcinoma. The most accurate and reliable specimen type used for EGFR mutation detection is tumor tissue (Liu et al., 2009; Luan et al., 2010). However, more than $70 \%$ of lung adenocarcinoma patients have advanced non-operable disease at diagnosis, making it difficult to obtain tissue samples. An international study showed that only about $30 \%$ of lung adenocarcinoma tissue specimens can be used to detect EGFR mutations (Sun et al., 2014). Thus, finding a different lung tissue sample type for use in reliable EGFR mutation detection is a major hurdle. In the present study, PCR amplification and gene sequencing were used to detect EGFR mutations in exons 18, 19, 20, and 21 in tumor tissue and pleural effusion specimens from 50 patients with advanced lung adenocarcinoma to investigate the different rates of EGFR mutations in the different sample types.

\section{MATERIAL AND METHODS}

\section{Materials}

Lung tissue and pleural effusion samples from 50 advanced lung adenocarcinoma patients were collected between January 2013 and July 2014 in Weifang People's Hospital. All of the enrolled patients were diagnosed by pathology combined with ipsilateral pleural effusion, and all lung cancers met the criteria for stage IV according to the 2011 Union for International Cancer Control (UICC). The enrolled patients included 22 males with an average age of $47 \pm 2.6$ years and 28 females with an average age of $45 \pm 3.2$ years. There were 18 male and 8 female smokers enrolled. All patient participation was voluntary, and signed written consent was obtained from all study participants.

\section{Experimental methods}

\section{Paraffin specimen extraction and digestion}

Paraffin-embedded lung tissue specimens were heated at $65^{\circ} \mathrm{C}$ for $60 \mathrm{~min}$, and then 
dewaxed with xylene. After the xylene was removed with anhydrous ethanol, tumor cells were collected via cell scraping. Tumor cells were then incubated with $200 \mu \mathrm{L}$ Buffer TL and $20 \mu \mathrm{L}$ Proteinase $\mathrm{K}$ at $55^{\circ} \mathrm{C}$ for $6-8 \mathrm{~h}$.

\section{DNA extraction and purification}

DNA was extracted using a DNA extraction kit (CW Biotech, Beijing, China) according to manufacturer instructions. Polyacrylamide gels were purchased from Jiangyuan Technology Co., Ltd. (Tianjin, China). Polyacrylamide gel electrophoresis was used to separate DNA fragments.

\section{PCR}

DNA polymerase was purchased from Generay Co., Ltd. (Shanghai, China). The cycling conditions consisted of an initial denaturation at $95^{\circ} \mathrm{C}, 1 \mathrm{~min}$ for annealing and 10 cycles of $1 \mathrm{~min}$ for extension, followed by 30 cycles of $50 \mathrm{~s}$ at $95^{\circ} \mathrm{C}, 60 \mathrm{~s}$ at $62^{\circ} \mathrm{C}$, and $60 \mathrm{~s}$ at $72^{\circ} \mathrm{C}$, and finally 10 min at $72^{\circ} \mathrm{C}$ for extension. The PCR products were separated by agarose gel electrophoresis and purified using an agarose gel extraction kit (Sunshine Bio, Nanjing, China).

\section{Sequencing}

The ABI 3730xI DNA analyzer (Applied Biosystems, Carlsbad, CA, USA) was used for sequencing analysis of the purified PCR products.

\section{Statistical analysis}

Data are reported as means \pm standard deviation (SD). All statistical analyses were performed using the SPSS 17.0 software (Chicago, IL, USA). Differences between the two tissue types were analyzed using a Student $t$-test. Enumeration data were analyzed by the chi-square test and the Fisher exact test with $\mathrm{P}<0.05$ considered statistically significant.

\section{RESULTS}

EGFR gene mutations (in exons 18, 19, 20, and 21) in tissue samples are shown in Table 1. In tissue samples, the EGFR mutation rate in exon 19 was significantly higher than that in the other three exons $(P<0.05)$, while the EGFR mutation rate in exon 21 was higher than that in exons 18 and $20(P<0.05)$. EGFR gene mutations (in exons 18, 19, 20, and 21) in pleural effusions are shown in Table 2. In pleural effusion samples, the EGFR mutation rate in exon 19 was significantly higher than that in the other three exons $(P<0.05)$, while the EGFR mutation rate in exon 21 was significantly higher than that in exons 18 and 20 ( $P<$ 0.05). A comparison of the EGFR mutation rates in tumor tissue and pleural effusion samples from advanced lung adenocarcinomas is shown in Table 3. Although the tissue samples had a slightly higher EGFR mutation rate compared to pleural effusion samples, the difference was not statistically significant $(P>0.05)$. 
Table 1. EGFR gene mutations in tissue samples.

\begin{tabular}{l|c|c}
\hline Group & Cases & \% Mutation rate (N) \\
\hline Exon $18^{\mathrm{C}}$ & 50 & $0(0 / 50)$ \\
\hline Exon $19^{\mathrm{A}}$ & 50 & $22.0(11 / 50)$ \\
\hline Exon $20^{\mathrm{D}}$ & 50 & $0(0 / 50)$ \\
\hline Exon $21^{\mathrm{B}}$ & 50 & $12.0(6 / 50)$ \\
\hline
\end{tabular}

$A$ is significantly higher than $B, C$, and $D, P<0.05$; $B$ is significantly higher than $C$ and $D, P<0.05$.

Table 2. EGFR gene mutations in pleural effusions.

\begin{tabular}{l|c|c}
\hline Group & Cases & \% Mutation rate (N) \\
\hline Exon $18^{\mathrm{C}}$ & 50 & $0(0 / 50)$ \\
\hline Exon $19^{\mathrm{A}}$ & 50 & $20.0(10 / 50)$ \\
\hline Exon $20^{\mathrm{D}}$ & 50 & $0(0 / 50)$ \\
\hline Exon $21^{\mathrm{B}}$ & 50 & $10.0(5 / 50)$ \\
\hline
\end{tabular}

$A$ is significantly higher than $B, C$, and $D, P<0.05$; $B$ is significantly higher than $C$ and $D, P<0.05$.

Table 3. Comparison of EGFR mutation rates in different sample types.

\begin{tabular}{l|c|c}
\hline Group & Cases & \% Mutation rate (N) \\
\hline Tissue samples & 50 & $34.0(17 / 50)$ \\
\hline Pleural effusion samples & 50 & $30.0(15 / 50)$ \\
\hline
\end{tabular}

$P>0.05$.

Lung adenocarcinoma cell pathology is shown in Figure 1. Specifically, columnar and new cubic cells composed of adenoid structures can be seen under microscopy, with enlarged nuclei and clear nucleolus structures. A sequencing map of EGFR mutations in tissue samples is shown in Figure 2, and the microphthalmia locus (MI locus) mutation in exon 19 is shown. A sequencing map of EGFR mutations in pleural fluid is shown in Figure 3, as well as the L858R mutation in exon 21.

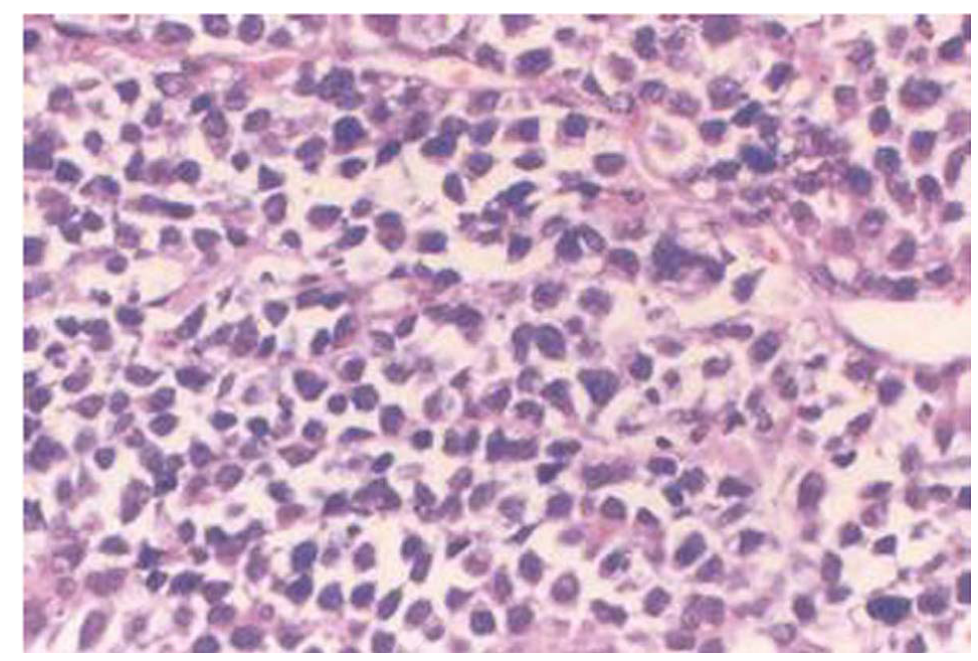

Figure 1. Lung adenocarcinoma pathology, HE staining, 100X magnification. 
30

40

50

60

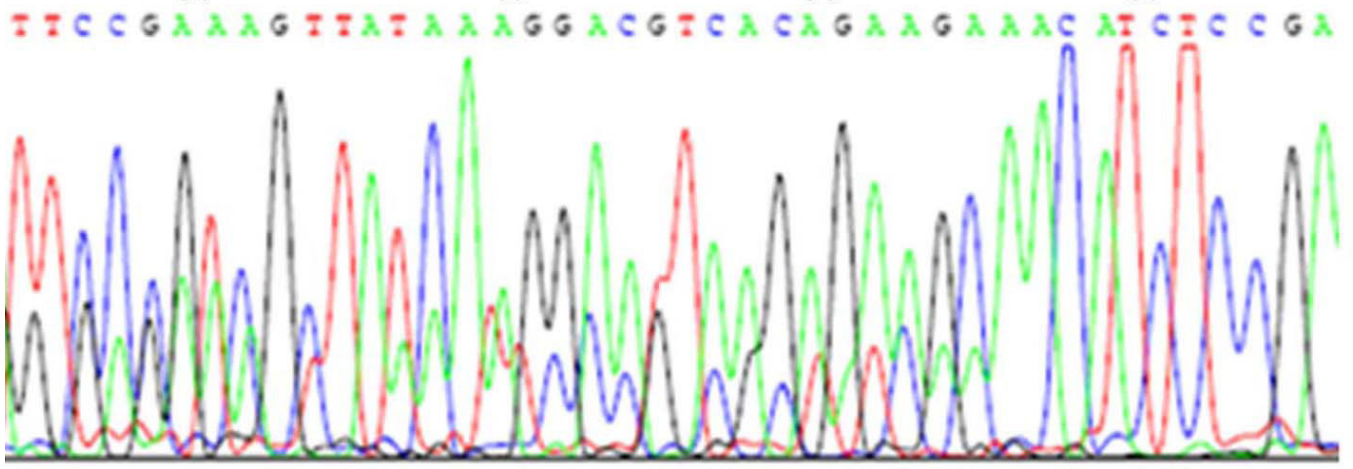

Figure 2. Sequencing map for a representative tissue sample mutation.
20
30
40
50

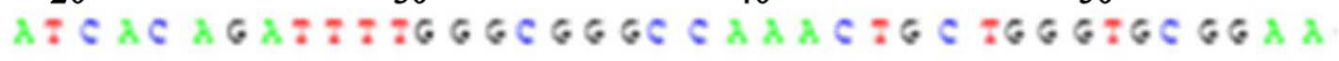

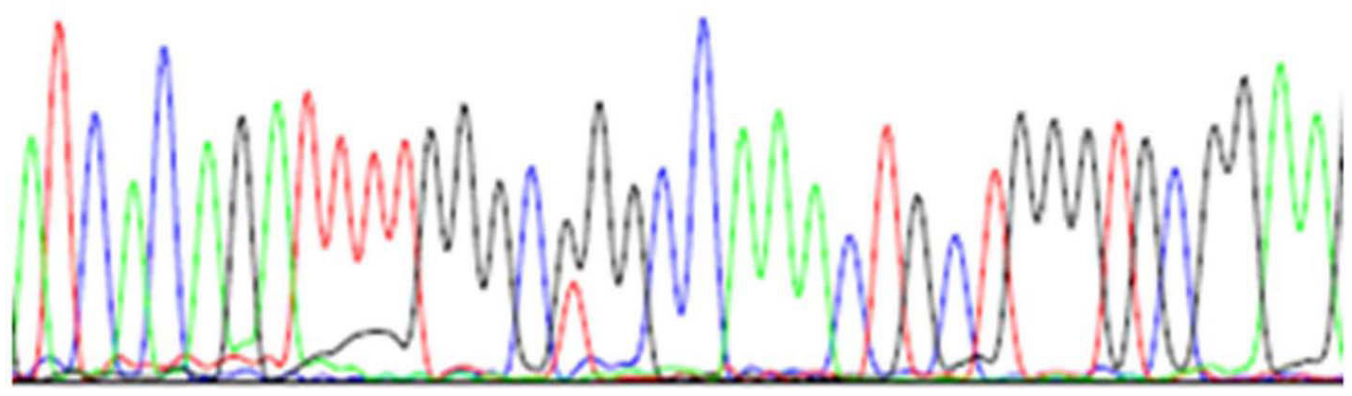

Figure 3. Sequencing map for a representative pleural fluid sample mutation.

\section{DISCUSSION}

Advanced non-small cell lung cancer, especially adenocarcinoma, currently has many treatment methods. Aside from systemic chemotherapy and local radiotherapy, EGFR tyrosine kinase inhibitors (EGFR-TKI) are becoming widely used in the clinical management of lung cancer (Koizumi et al., 2010; Simone et al., 2010; Brevet et al., 2011; Nakamura et al., 2011). EGFR is derived from the type I tyrosine kinase receptor family and shares homologies with HER2, HER3, and HER4. EGFR is composed of 28 exons and is located on the short arm of chromosome 7. EGFR has been shown to be widely distributed in the membranes of epidermal cells and is composed of three regions that include the intracellular, transmembrane, and extracellular domains (Yoo et al., 2010). EGFR has mainly been implicated in the following four signaling pathways: JAK-STAT, PI3K-PDK, PLC- $\gamma$, and RAS-RAF-MEK-ERK-MAPK (Qi et al., 2014).

Although promising, EGFR-TKI can only exhibit their inhibitory effects on tumor growth to promote prolonged survival in patients with EGFR mutations. The intracellular tyrosine kinase of EGFR is comprised of the four exons 18, 19, 20, and 21 (Cheng et al., 2014). Among the four 
exons, deletions in exon 19 and mutations in exon 21 are the most common, as previous studies found that exon 19 deletions accounted for $48 \%$ and exon 21 mutations account for $43 \%$ of all EGFR genetic changes (Agwa and Ma, 2014).

Mutations in EGFR are mainly detected in tumor tissue and hydrothorax samples (i.e., cytology), of which tumor tissue is still most commonly used. However, as most lung cancers are found to be advanced upon diagnosis and cannot be surgically resected and samples obtained by bronchoscope or percutaneous lung biopsy are too small to use for EGFR mutation detection, new sample types to replace or supplement tissue samples to detect EGFR mutations have become a focus of current research.

Zhao et al. (2011) found that the total EGFR mutation rate was $30 \%$ in tissue specimens from 100 patients with lung adenocarcinoma, including 16\% with exon 19 deletions, 13\% with exon 21 mutations, and 1\% with exon 20 mutations. The total EGFR mutation rate was slightly lower than our results in tissue samples (34\%), which may be associated with the limited number of patients enrolled in our study.

In comparison to tissue EGFR mutations in the aforementioned study, Billah et al. (2011) found that the total EGFR mutation rate in pleural effusion samples was $29 \%$ in 300 cases of patients with lung adenocarcinoma, including $16 \%$ with exon 19 deletions, $12 \%$ with exon 21 mutations, and $1 \%$ with exon 20 mutations. Lozano et al. (2011) reported similar results, where the total EGFR mutation rate was $26 \%$ in pleural fluid specimens from 200 lung adenocarcinoma patients, including $12 \%$ with exons 19 deletions, $11 \%$ with exon 21 mutations, and $3 \%$ with exon 20 mutations.

In the present study, 50 tissue samples and pleural fluid samples were collected from patients clinically diagnosed with lung adenocarcinoma by pathology combined with malignant pleural effusion. PCR and direct sequencing were used to identify EGFR mutations in both lung tissue and pleural effusion samples. The results showed that the overall EGFR mutation rate was $34 \%$ in tissue samples, which was slightly higher than the EGFR mutation rate in pleural effusion samples $(30 \%)$, but this difference was not statistically significant. These results are consistent with previous studies. The mutation rate in exon 19 was significantly higher than that in the other three exons $(18,20,21)$, regardless of the sample type $(P<0.05)$. The mutation rate in exon 21 was higher than that in exons 18 and $20(P<0.05)$. We failed to detect exon 20 mutations, which have been identified in previous reports, but this may be attributed to the limited number of patients enrolled herein. Hence, a larger sample size is needed for follow-up investigations.

In conclusion, our results revealed that tissue samples and pleural effusion samples have similar EGFR mutation rates in advanced lung cancer. Thus, pleural effusion samples may become a candidate specimen for detecting EGFR mutations as a complement to tissue samples.

\section{Conflicts of interest}

The authors declare no conflict of interest.

\section{ACKNOWLEDGMENTS}

We thank the anonymous reviewers for reviewing this manuscript.

\section{REFERENCES}

Agwa ES and Ma PC (2014). Targeting the MET receptor tyrosine kinase in non-small cell lung cancer: emerging role of tivantinib. Cancer Manag. Res. 6: 397-404. 
Billah S, Stewart J, Staerkel G, Chen S, et al. (2011). EGFR and KRAS mutations in lung carcinoma: molecular testing by using cytology specimens. Cancer Cytopathol. 119: 111-117.http://dx.doi.org/10.1002/cncy.20151

Brevet M, Johnson ML, Azzoli CG and Ladanyi M (2011). Detection of EGFR mutations in plasma DNA from lung cancer patients by mass spectrometry genotyping is predictive of tumor EGFR status and response to EGFR inhibitors. Lung Cancer 73: 96-102.http://dx.doi.org/10.1016/j.lungcan.2010.10.014

Cheng LB, Chen CM, Zhong H and Zhu LJ (2014). Squamosamide derivative FLZ protects retinal pigment epithelium cells from oxidative stress through activation of epidermal growth factor receptor (EGFR)-AKT signaling. Int. J. Mol. Sci. 15: 18762-18775. http://dx.doi.org/10.3390/ijms151018762

Fukuoka M, Wu YL, Thongprasert S, Sunpaweravong P, et al. (2011). Biomarker analyses and final overall survival results from a phase III, randomized, open-label, first-line study of gefitinib versus carboplatin/paclitaxel in clinically selected patients with advanced non-small-cell lung cancer in Asia (IPASS). J. Clin. Oncol. 29: 2866-2874. http://dx.doi.org/10.1200/ JCO.2010.33.4235

He C, Liu M, Zhou C, Zhang J, et al. (2009). Detection of epidermal growth factor receptor mutations in plasma by mutantenriched PCR assay for prediction of the response to gefitinib in patients with non-small-cell lung cancer. Int. J. Cancer 125: 2393-2399. http://dx.doi.org/10.1002/ijc.24653

Jiang B, Liu F, Yang L, Zhang W, et al. (2011). Serum detection of epidermal growth factor receptor gene mutations using mutant-enriched sequencing in Chinese patients with advanced non-small cell lung cancer. J. Int. Med. Res. 39: 13921401. http://dx.doi.org/10.1177/147323001103900425

Koizumi W, Akiya T, Sato A, Sakuyama T, et al. (2010). Phase II study of S-1 as first-line treatment for elderly patients over 75 years of age with advanced gastric cancer: the Tokyo Cooperative Oncology Group study. Cancer Chemother. Pharmacol. 65: 1093-1099. http://dx.doi.org/10.1007/s00280-009-1114-6

Liu YY, Wang R, Jia ZP, Guo ZA, et al. (2009). H-ras gene mutation detection of gastric cancer by restriction fragment length polymorphism with capillary electrophoresis. Acta Chimi. Sin. 67: 323-328.

Lozano MD, Zulueta JJ, Echeveste JI, Gúrpide A, et al. (2011). Assessment of epidermal growth factor receptor and K-ras mutation status in cytological stained smears of non-small cell lung cancer patients: correlation with clinical outcomes. Oncologist 16: 877-885. http://dx.doi.org/10.1634/theoncologist.2010-0155

Luan HL, Sun LN, Dong N, Guo Y, et al. (2010). Study of the correlation of EGFR and K-RAS gene mutations with its protein expression in non small cell lung cancer. Clin. Oncol. Cancer Res. 7: 97-102.

Mitsudomi T, Morita S, Yatabe Y, Negoro S, et al.; West Japan Oncology Group (2010). Gefitinib versus cisplatin plus docetaxel in patients with non-small-cell lung cancer harbouring mutations of the epidermal growth factor receptor (WJTOG3405): an open label, randomised phase 3 trial. Lancet Oncol. 11: 121-128. http://dx.doi.org/10.1016/S1470-2045(09)70364-X

Nakamura T, Sueoka-Aragane N, Iwanaga K, Sato A, et al. (2011). A noninvasive system for monitoring resistance to epidermal growth factor receptor tyrosine kinase inhibitors with plasma DNA. J. Thorac. Oncol. 6: 1639-1648. http://dx.doi. org/10.1097/JTO.0b013e31822956e8

Qi WX, Fu S, Zhang Q, Guo XM, et al. (2014). Anti- EGFR agents and complete responses in the treatment of advanced non-small-cell lung cancer: a meta-analysis of 17 phase III randomized controlled trials. Curr. Med. Res. Opin. 31: 1-19.

Simone G, Mangia A, Malfettone A, Rubini V, et al. (2010). Chromogenic in situ hybridization to detect EGFR gene copy number in cell blocks from fine-needle aspirates of non small cell lung carcinomas and lung metastases from colo-rectal cancer. J. Exp. Clin. Cancer Res. 29: 125. http://dx.doi.org/10.1186/1756-9966-29-125

Sun Z, Wang Z, Liu X, et al. (2014). New development of inhibitors targeting the PI3K/AKT/mTOR pathway in personalized treatment of non-small-cell lung cancer. Anticancer Drugs.

Yoo SB, Lee HJ, Park JO, Choe G, et al. (2010). Reliability of chromogenic in situ hybridization for epidermal growth factor receptor gene copy number detection in non-small-cell lung carcinomas: a comparison with fluorescence in situ hybridization study. Lung Cancer 67: 301-305. http://dx.doi.org/10.1016/j.lungcan.2009.05.002

Zhang J, Liang ZY, Gao J and Liu TH (2010). Relationship between the mutations of epidermal growth factor receptor gene and k- ras gene and the clinicopathological features of non- small cell lung cancers. Med. J. Peking Union Med. Coll. Hosp 1: 53-59.

Zhao J, Zhao J, Huang J, Chen Y, et al. (2011). A novel method for detection of mutation in epidermal growth factor receptor. Lung Cancer 74: 226-232. http://dx.doi.org/10.1016/j.lungcan.2011.02.015

Zhu CQ, da Cunha Santos G, Ding K, Sakurada A, et al.; National Cancer Institute of Canada Clinical Trials Group Study BR.21 (2008). Role of KRAS and EGFR as biomarkers of response to erlotinib in National Cancer Institute of Canada Clinical Trials Group Study BR.21. J. Clin. Oncol. 26: 4268-4275. http://dx.doi.org/10.1200/JC0.2007.14.8924 